ORIGINAL ARTICLE

\title{
Frequency of Ischemic Heart Disease in Patients of End Stage Renal Disease
}

\author{
MUHAMMAD FARHAN AKHTAR ${ }^{1}$, HAFIZ MUHAMMAD WAQAS SIDDQUE ${ }^{2}$, TALHA NAZIR ${ }^{3}$, UBAID KHAN ${ }^{4}$ \\ ${ }^{1-3}$ House Officer, Department of Medicine, King Edward Medical University/ Mayo Hospital, Lahore \\ ${ }^{4}$ Final Year MBBS, King Edward Medical University, Lahore. \\ Correspondence to: Muhammad Farhan Akhtar, Email: farriqaisrani@gmail.com, Cell: 0306-1112004
}

\begin{abstract}
Introduction: The disease burden of Chronic Kidney Disease (CKD) is increasing every day and adding the burden on our healthcare system. Many patients are being treated by hemodialysis due to a very limited recourses available. Cardiovascular complications such as ischemic heart disease (IHD) are very common in patients who are being treated by hemodialysis and one of the leading causes of death in these patients.

Objective: Frequency of IHD in the patients of ESRD.

Methodology: Cross-sectional type of study was piloted for duration of three months from April 2019 to June 2019 in Nephrology Department Mayo Hospital Lahore. Eighty one patients were recruited who fulfilled the inclusion criteria i.e. patients suffering end stage renal disease on maintenance hemodialysis through nonprobability, convenient sampling. A standard questionnaire was used to collect the data. All the data was analyzed by using SPSS (software package for statistical analysis) version 20.

Results: The study was carried out among 81 patients with diagnosis of Chronic Kidney Disease on the maintenance hemodialysis. Most patients in study were falling in the range of 21-60 years. The study included 46 $(56.8 \%)$ males and $35(43.2 \%)$ females. The frequency of Ischemic Heart Diseases in these patients was found to be $56.8 \%$ (46/81 cases).

Conclusion: Both genders are equally affected. The frequency of IHD in patients of end stage renal disease who are on hemodialysis is observed to be high, but not as much high as observed in previous studies. Both genders are affected almost equally.

Key Words: Ischemic Heart Disease, End stage renal disease, chronic kidney disease, Hemodialysis.
\end{abstract}

\section{INTRODUCTION}

Chronic kidney disease (CKD) is a global public health issue and it is growing over time ${ }^{1}$. A great proportion of the CKD patients may develop end stage renal disease (ESRD). Most of the patients of ESRD having access to renal replacement therapy are treated by hemodialysis ${ }^{2}$.

Cardiovascular diseases are major concerns for the patients suffering from end stage renal disease, particularly those, which are on hemodialysis. It is principal cause of the death amongst patients suffering from chronic kidney disease, particularly in dialysis population. It accounts for almost $50 \%$ of all deaths occurring due to a known cause in patients undergoing dialysis ${ }^{3},{ }^{4}$. Among all the cardiovascular diseases ischemic heart disease (IHD) are considered as chief cause of the mortality as well as morbidity in the patients of chronic kidney disease [4]. Lindner et al. identified that $35 \%$ of the deaths in the patients of end stage renal failure undergoing hemodialysis are because of coronary artery disease ${ }^{5}$.

Ischemic heart disease has a high occurrence in the patients having end stage renal disease besides has a noticeable impact on the prognosis ${ }^{6}$. Evidence is present which indicates that a portion of this cardiovascular damage may be due to hemodialysis. It is because it causes hemodynamic instability through the development of subclinical $\mathrm{Ml}^{7}$. While on hemodialysis, atherosclerotic process accelerates and probability of the coronary artery calcification increases with extended duration of the dialysis ${ }^{8}$. Incidence of the coronary artery disease in the patients with starting of dialysis is equal to the $38 \%$ with the comparative risk up to 5 to 20 folds, of overall population ${ }^{9}$.

Cardiovascular disease occurring along with chronic kidney disease might be attributed to comorbidities for instance diabetes mellitus, obesity, hypertension, dyslipidemias, and smoking ${ }^{10}$. However, CKD itself is deliberated as an autonomous risk factor in advancement of chronic CVD due to a number of pathological processes associated with it i.e. increased vascular calcification ${ }^{11}$, inflammatory process, uremic environment, endothelial dysfunction, high oxidative stress ${ }^{12,}{ }^{13}$, over hydration \& hypertension, cardiac hypertrophy and anemia ${ }^{14}$.

A latest study in Karachi presented that frequency of the ischemic heart disease in the patients suffering from chronic kidney disease on the maintenance hemodialysis to be observed in $70 \%$ of cases (112/160 cases) ${ }^{15}$. Another study in Pakistan has showed that $49 \%$ of the patients of CKD have findings of asymptomatic coronary artery disease $^{16}$. In USA, the incidence of IHD in the hemodialysis patients is $41 \%{ }^{17}$. Locatelli $\mathrm{F}$ et al. described that IHD was existing in $18.6 \%$ of incident ESRD patients ${ }^{18}$.

The incidence of ESRD patients getting hemodialysis is growing over time; though prevalence of IHD in such patients continues to be assessed. Thus, our research had the goal of determining the frequency of IHD in these patients. Rationale of our study was to assess that a large number of ESRD patients suffer from ischemic heart disease. So if the study results show huge burden of IHD in ESRD population then as a rule in future this high risk population should be screened for IHD and if required intervention should be done to decrease the mortality in such population.

\section{METHODOLOGY}

Cross-sectional type of study was piloted for duration of 3 months from April 2019 to June 2019 in Nephrology Department Mayo Hospital Lahore. 81 patients were 
recruited from Nephrology Department, Mayo Hospital Lahore who fulfilled the inclusion criteria i.e. patients with end stage renal disease on maintenance hemodialysis through non-probability, convenient sampling. A standard questionnaire was used to collect the data. Participants were explained the benefits and possible risks and ensured that their personal information would be kept confidential. The response rate by the participants was $100 \%$. All the data was analyzed by using SPSS (software package for statistical analysis) version 20. Descriptive analysis and cross tabs were used to obtain the result. Cross sectional study design was used to conduct this research.

Study Design: Cross Sectional Study.

Study Duration: Three months after approval of synopsis.

Study Setting: Nephrology Department, Mayo Hospital, Lahore.

Sampling Technique: Non-probability, convenient sampling

Data Collection Tool: Questionnaire based

Study Population: Patients of the end stage renal disease on maintenance hemodialysis at Nephrology Department, Mayo Hospital Lahore.

Sample Size: Sample size of 81 patients is estimated by using $95 \%$ confidence level, $10 \%$ absolute precision with expected \%age ischemic heart disease patients as $70 \%$.

$$
n=\frac{Z_{1-a / 2}^{2}-p \cdot q}{d^{2}}
$$

$Z_{1-a / 2}^{2}=$ Confidence level $95 \%=1.96$

$p=$ Prevalence $=70 \%$

$q=1-p$

$d=$ absolute precision $=10 \%$

Sample Selection:

Inclusion Criteria:

- All the patients of end stage renal disease on maintenance hemodialysis.

Exclusion Criteria:

- Critically ill, unconscious or non-cooperative patients.

Data Collection Procedures: Data was collected from the patients of End Stage Renal disease on maintenance hemodialysis at Nephrology Department, Mayo Hospital Lahore. Participants were selected by non-probability, convenient sampling.

Data was collected using pre-designed, pre-tested pro forma. This included patients' demographic information, history of CKD and hemodialysis, history of comorbidities, investigational evaluation and history of ischemic heart disease.

The collected information was recorded directly on the pro forma. Questions related to chronic kidney disease, hemodialysis and ischemic heart disease were asked from every patient and their response was recorded on the given pro forma.

Data Analysis Procedure: Data was entered in SPSSversion 20. Quantitative variables i.e. age was presented as mean \pm S.D. Qualitative variables i.e. gender was presented as frequency and percentages.

\section{RESULTS}

The study was carried out among 81 patients with diagnosis of Chronic Kidney Disease on the maintenance hemodialysis. Most patients included in our study were in the range of 21-60 years of age. (Fig 1).

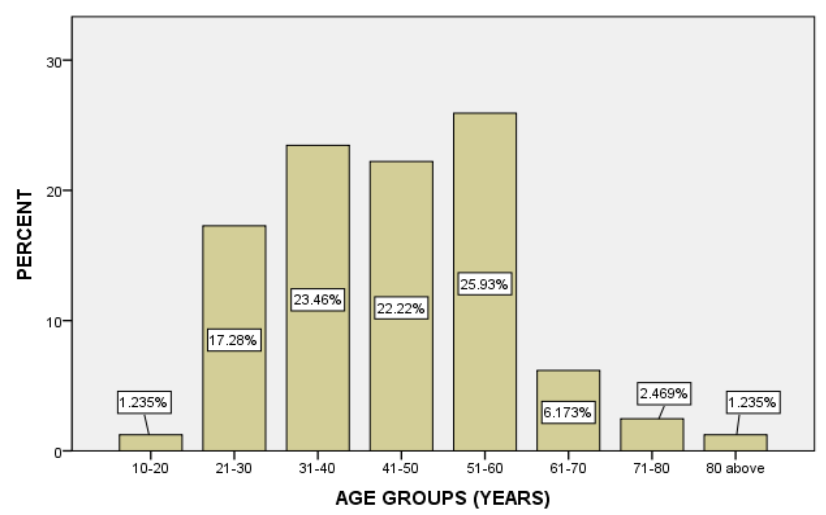

Figure 1: Age Distribution of the Patients $n=81$

The mean age was $45.35 \pm 14.163$. The study included 46 $(56.8 \%)$ males and $35(43.2 \%)$ females (Table 1, Fig 2).

\begin{tabular}{|l|l|l|l|l|}
\hline \multicolumn{5}{|c|}{ Table 1: Gender distribution of the patients $\mathrm{n}=81$} \\
\hline & Frequency & Percent & Valid Percent & $\begin{array}{l}\text { Cumulative } \\
\text { Percent }\end{array}$ \\
\hline Male & 46 & 56.8 & 56.8 & 56.8 \\
\hline Female & 35 & 43.2 & 43.2 & 100.0 \\
\hline Total & 81 & 100.0 & 100.0 & \\
\hline
\end{tabular}

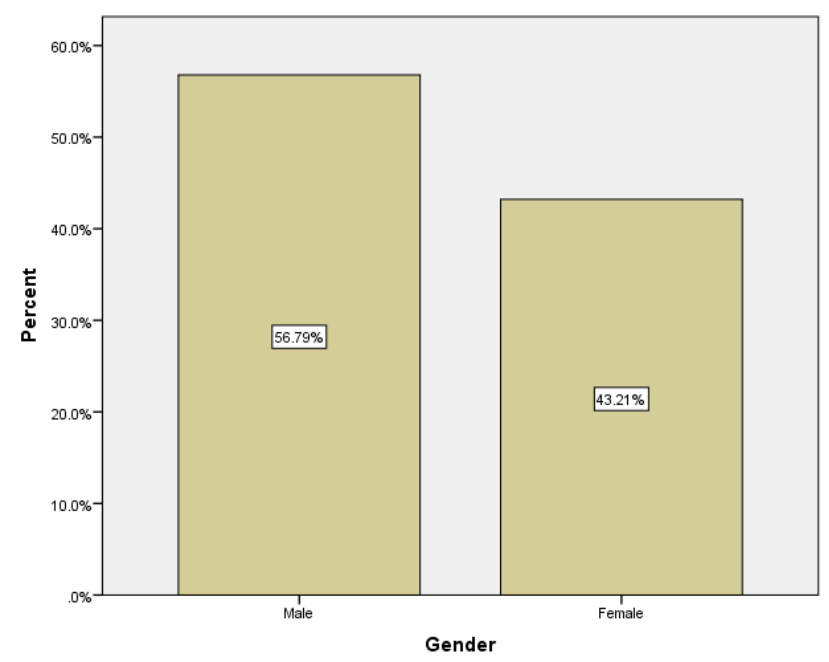

Figure 2: Gender Distribution of the Patients $n=81$

The frequency of Ischemic Heart Diseases in these patients was found to be $56.8 \%$ (46/81 cases) (Table 3, Fig 3).

\begin{tabular}{|l|l|l|l|l|}
\hline \multicolumn{5}{|c|}{ Table 3: Ischemic Heart Disease in patients of ESRD $\mathrm{n}=81$} \\
\hline & Frequency & Percent & Valid Percent & $\begin{array}{l}\text { Cumulativ } \\
\text { e Percent }\end{array}$ \\
\hline Positive & 46 & 56.8 & 56.8 & 56.8 \\
\hline Negative & 35 & 43.2 & 43.2 & 100.0 \\
\hline Total & 81 & 100.0 & 100.0 & \\
\hline
\end{tabular}




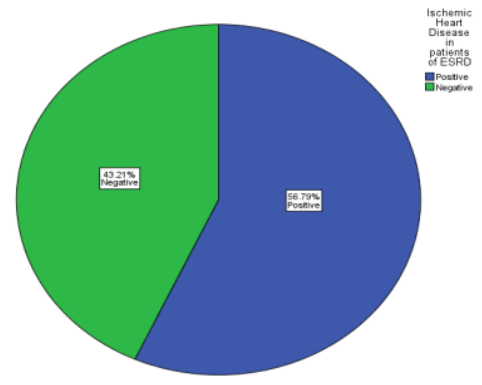

Figure 1: Frequency of IHD in Patients of ESRD $n=81$

\section{DISCUSSION}

Heart disease is considered as prevalent cause of death among patients of CKD on maintenance hemodialysis, responsible for approximately $45 \%$ of the total deaths reported in United States. The incidence of cardiovascular deaths among dialysis patients is 10-20 times greater if compared with general population ${ }^{15}$. This high mortality is attributed, in part, to high occurrence of the cardiac disease before starting dialysis and high frequency of risk factors for cardiac diseases in patients of CKD ${ }^{19}$. Moreover, case casualty rate in patients of dialysis with the cardiac disease is higher than patients of non-dialysis suffering from cardiac disease ${ }^{20}$.

In our project the total of 81 patients with CKD diagnosis of were studied, there were $56.8 \%$ male and $43.2 \%$ female patients. Rate of the Ischemic Heart Disease was slightly greater in male cases as compared to females. In a similar study conducted in Karachi, rate of IHD was significantly higher in males as compared to females (76.5\% vs. $58.6 \%$ ).

Similarly, report from the "European Heart Survey" on the stable angina depicted that functional testing for IHD and rate of angiography along with interventional procedures is much less in women compared with men ${ }^{21}$.

In our study frequency of IHD in the patients with CKD on maintenance hemodialysis came to be $56.8 \%(46 / 81)$. While Pooran Mal et al. conducted a similar study and their results showed a frequency of $70 \%$ of IHD in patients with CKD on the maintenance hemodialysis ${ }^{15}$.

Another significant finding of our study was, frequency of hypertension in CKD patients was $93.5 \%$, a significant figure while.

\section{CONCLUSION}

Frequency of the Ischemic Heart Disease among Chronic Kidney Disease Patients on the maintenance hemodialysis is observed to be high, but not as much high as observed in previous studies. Both genders are affected almost equally. However great proportion of the patients suffering from Chronic Kidney Disease on maintenance dialysis showed previous history of Hypertension.

\section{REFERENCES}

1. Schieppati A, Remuzzi G. Chronic renal diseases as a public health problem: epidemiology, social, and economic implications. Kidney International. 2005 Sep 1;68:S7-10.
2. US Renal Data System. USRDS 2013 annual data report: atlas of chronic kidney disease and end-stage renal disease in the United States. National Institutes of Health, National Institute of Diabetes and Digestive and Digestive and Kidney Diseases, Vol. 2014. 2013.

3. Bhatti NK, Karimi Galougahi K, Paz Y, Nazif T, Moses JW, Leon MB, Stone GW, Kirtane AJ, Karmpaliotis D, Bokhari S, Hardy MA Diagnosis and management of cardiovascular disease in advanced and end-stage renal disease. Journal of the American Heart Association. 2016 Aug 4;5(8):e003648.

4. Choi HY, Park HC, Ha SK. How do we manage coronary artery disease in patients with CKD and ESRD?. Electrolytes \& Blood Pressure: E \& BP. 2014 Dec;12(2):41.

5. Lindner A, Charra B, Sherrard DJ, Scribner BH. Accelerated atherosclerosis in prolonged maintenance hemodialysis. New England Journal of Medicine. 1974 Mar 28;290(13):697-701.

6. Parfrey PS, Foley RN, Harnett JD, Kent GM, Murray D, Barre PE. Outcome and risk factors of ischemic heart disease in chronic uremia. Kidney international. 1996 May 1;49(5):1428-34.

7. Sağ S, Yeşilbursa D, Yıldız A, Dilek K, Şentürk T, Serdar OA Aydınlar A. Acute hemodialysis-induced changes in tissue Doppler echocardiography parameters. Balkan medical journal. 2014 Sep;31(3):239.

8. Goodman WG, Goldin J, Kuizon BD, Yoon C, Gales B, Sider D, Wang Y, Chung J, Emerick A, Greaser L, Elashoff RM. Coronaryartery calcification in young adults with end-stage renal disease who are undergoing dialysis. New England Journal of Medicine. 2000 May 18;342(20):1478-83.

9. Stack AG, Bloembergen WE. A cross-sectional study of the prevalence and clinical correlates of congestive heart failure among incident US dialysis patients. American journal of kidney diseases. 2001 Nov 1;38(5):992-1000.

10. Cervellin G, Lippi G. Of Mls and men-a historical perspective on the diagnostics of acute myocardial infarction. In Seminars in thrombosis and hemostasis 2014 Jul (Vol. 40, No. 05, pp. 535-543). Thieme Medical Publishers.

11. Moe SM, Chen NX. Mechanisms of vascular calcification in chronic kidney disease. Journal of the American Society of Nephrology. 2008 Feb 1;19(2):213-6.

12. Hage FG, Venkataraman R, Zoghbi GJ, Perry GJ, DeMattos AM, Iskandrian $A E$. The scope of coronary heart disease in patients with chronic kidney disease. Journal of the American College of Cardiology. 2009 Jun 9;53(23):2129-40.

13. Wanner C, Metzger T. C-reactive protein a marker for all-cause and cardiovascular mortality in hemodialysis patients. Nephrology Dialysis Transplantation. 2002 Aug 1;17(suppl_8):29-32.

14. Tanaka $Y$, Joki $N$, Hase $H$. Ischemic heart disease in patients with end-stage kidney disease. Blood purification. 2015;40(4):332-6.

15. Shera MT, Shayan A, Jilanee SD, Shabu MM, Khan A. Frequency of Ischemic Heart Disease in Patients with End Stage Renal Disease. Journal of Biomedical Research \& Environmental Sciences. 2019 May 9;5(5):001-4.

16. Khana MI, Rashidb MA, Imranb MA, Hussainb A, Noemanb A, Ayubb M. Prevalence Of Asymptomatic Coronary Artery Disease On $99 \mathrm{~m}$ TC-sesTAmlbl spect In Chronic Kidney Disease Patients. The Journal. 2015;13(1):19.

17. Parfrey PS, Foley RN. The clinical epidemiology of cardiac disease in chronic renal failure. Journal of the American Society of Nephrology. 1999 Jul 1;10(7):1606-15.

18. Locatelli F, Marcelli D, Conte F, Del Vecchio L, Limido A, Malberti F, Spotti D, Sforzini S. Patient selection affects end-stage renal disease outcome comparisons. Kidney International. 2000 Jan 1;57:S94-9.

19. Fung F, Sherrard DJ, Gillen DL, Wong C, Kestenbaum B, Seliger S, Ball A, Stehman-Breen C. Increased risk for cardiovascular mortality among malnourished end-stage renal disease patients. American journal of kidney diseases. 2002 Aug 1;40(2):307-14.

20. Herzog CA, Ma JZ, Collins AJ. Poor long-term survival after acute myocardial infarction among patients on long-term dialysis. New England Journal of Medicine. 1998 Sep 17;339(12):799-805.

21. Daly CA, Clemens F, Sendon JL, Tavazzi L, Boersma E, Danchin N, Delahaye F, Gitt A, Julian D, Mulcahy D, Ruzyllo W. The clinical characteristics and investigations planned in patients with stable angina presenting to cardiologists in Europe: from the Euro Heart Survey of Stable Angina. European heart journal. 2005 May 1;26(10):996-1010. 